\title{
REVISÃO SISTEMÁTICA SOBRE LETRAMENTO DIGITAL NA FORMAÇÃO DE PROFESSORES
}

\author{
SYSTEMATIC REVIEW ON DIGITAL LITERACY IN TEACHER TRAINING
}

\author{
Késsia Mileny de Paulo Moura \\ Universidade Federal do Maranhão / Universidade Federal do Rio Grande do Sul, Brasil \\ kessiaita@gmail.com
}

RESUMO: Pesquisar a inserção das tecnologias digitais da informação e comunicação nos contextos formativos envolve problematizar as percepções, apropriações e significações de professores e alunos sobre a questão. Este texto buscou identificar as produções científicas brasileiras (teses e dissertações) a respeito do letramento digital na formação de professores, realizadas entre os anos de 2010 a 2018. Utilizamos a revisão sistemática como procedimento metodológico, com o auxílio do software Parsifal. Pontuamos as seguintes equações para verificar nos trabalhos: quais objetivos de pesquisa essas produções revelam? Que perspectivas de letramento digital e quais procedimentos e instrumentos metodológicos os pesquisadores adotaram? Quais resultados dos processos de letramento digital trabalhados na formação de professores foram revelados? Como resultados, validamos 37 trabalhos, que apontam as configurações das propostas de formação com usos das tecnologias digitais que procuram responder às novas dinâmicas sociais para as quais os alunos-professores precisam estar aptos. De acordo com as pesquisas encontradas, os cursos de formação inicial ou continuada têm inserido as tecnologias digitais em suas práticas, mas as possibilidades de usos ainda são muitas.

PALAVRAS-CHAVE: letramento digital; formação de professores; revisão sistemática.

ABSTRACT: Researching the insertion of digital information and communication technologies in the formative contexts involves problematizing teachers and students' perceptions, appropriations and meanings about the issue. This text sought to identify the Brazilian scientific productions (theses and dissertations) regarding digital literacy in teacher education, between the years 2010 to 2018. We used the systematic review as a methodological procedure, with the help of the Parsifal software. We scored the following equations to verify the work: which research objectives do these productions reveal? What perspectives of digital literacy and what procedures and methodological instruments did the researchers adopt? What results of the digital literacy processes worked on in the training of teachers were revealed? As results, we validated 37 works, which point out the settings of training proposals with uses of digital technologies that seek to respond to the new social dynamics that student-teachers need to be able to. According to the research works found, the initial or continued training courses have lent themselves to insert the digital technologies, but the possibilities of uses are still many.

KEYWORDS: digital literacy; teacher training; systematic review. 


\section{Introdução}

As tecnologias digitais da informação e comunicação (TDIC) trouxeram outras dimensões para o viver em sociedade. De acordo com Moita-Lopes (2012), essas dimensões não podem ser evidenciadas somente pelos usos de tecnologias nas práticas sociais, mas sim, sobretudo, pela forma como essas práticas foram se modificando com os usos. O que vemos hoje são incorporações das tecnologias na maneira de pensar e de atuar em sociedade, na maneira de lidar com a informação, bem como na construção e na reprodução do conhecimento.

Esse último ponto nos remete às trajetórias de aprendizagem, que requerem outros formatos na atualidade, mas parece-nos que as instituições educativas não estão neste mesmo compasso. A escola ainda está em uma fase analógica, em detrimento dos processos comunicativos digitais que caracterizam os outros espaços da sociedade. No trabalho com os letramentos, por exemplo, a predominância que ainda se verifica nas escolas é da cultura do papel, enquanto o aluno tem outras práticas comunicativas, que envolvem a tela de um computador ou celular.

Nesse descompasso, é mister afirmar a urgência para que a escola, os professores, os currículos e metodologias educativas privilegiem a incorporação das tecnologias digitais de informação e comunicação de maneira que melhor atendam às prerrogativas de uma sociedade cada vez mais tecnologizada. Logo, a formação desse professor não pode estar alheia aos novos processos da dinâmica social a respeito das tecnologias, deve problematizá-las e incorporá-las às propostas formativas, possibilitando o desenho de um profissional que consiga dinamizar sua prática em função das novas necessidades educativas de seus alunos.

Da mesma forma, as pesquisas voltadas à educação não podem ignorar suas implicações e potencialidades na forma de pensar e estudar o processo educativo com o uso das tecnologias. Diante do exposto, apresentamos neste texto o resultado de uma revisão sistemática que buscou identificar as produções científicas brasileiras (teses e dissertações) a respeito do letramento digital na formação de professores, realizadas entre os anos de 2010 a 2018.

\section{Letramento digital}

Com o uso crescente de recursos e mídias digitais, novas exigências de aprendizagem são requeridas em alinhamento às necessidades dos novos modos de comunicação e, por conseguinte, de letramentos e linguagens que o tempo presente traz. Assim, o letramento traz complexidades e possibilidades ao processo de aprendizagem, dadas em formatos multimodais como resposta à nova conjuntura social mediada por tecnologias (BUZATO, 2006).

As práticas de leitura e escrita agora em tela acarretam implicações sobre o estado ou condição dos sujeitos letrados (SOARES, 2002), ampliam as formas de aprender a aprender, de acesso às leituras e às maneiras de escrever e socializar os textos. Nesse contexto, situa-se o letramento digital, que associa o domínio e a utilização competente da leitura e da escrita perante as tecnologias da informação e comunicação, compelindo outra forma de construir, organizar e divulgar conhecimentos, acepção que está 
fundamentada nos estudos dos novos letramentos de Lankshear; Knobel (2005), Gee (2009), Street (2014), Moita-Lopes (2012), Buzato (2009a) e Buzato (2009b).

Essas novas formas permitem a participação das pessoas em práticas letradas mediadas por dispositivos tecnológicos, produzindo e transfigurando sentidos e significados dos códigos culturais (BUZATO, 2009a). O autor concebe o fenômeno no plural, letramentos digitais, tratando como

não mais como tipos de letramento contrapostos aos tradicionais, mas como redes complexas e heterogêneas que conectam letramentos (práticas sociais), textos, sujeitos, meios e habilidades que se agenciam, entrelaçam, contestam e modificam mútua e continuamente, por meio, virtude ou influência das TIC (BUZATO, 2009a, p. 22).

Nos processos de aquisição de leitura e escrita, as TDIC demandam habilidades e competências que são "necessárias para que um indivíduo entenda e use a informação de maneira crítica e estratégica, em formatos múltiplos, vinda de variadas fontes e apresentada por meio do computador-internet" (FREITAS, 2010, p. 339-340). Fazer bom uso dos recursos tecnológicos no processo de letramento possibilita a reinvenção das ações e dos sujeitos a cada nova experiência.

Essas habilidades, segundo Xavier (2005, p. 5) pressupõem proficiência e compreensão para usar os equipamentos, visto que o letramento digital "traz consigo uma série de situações novas de comunicação nunca vividas antes da chegada das inovações tecnológicas computacionais". Cada novo aparato digital utilizado desempenha papéis de mediação na reconfiguração entre comunicação e linguagem, entre sujeitos, contextos e meios, que interagem e transformam suas ações (BUZATO, 2009a; SILVA, 2011; COUTINHO; LISBOA, 2011; KENSKI, 2007).

Para Cardon (2005), quem faz uso das TDIC acaba por apresentar um perfil que vai além de ser leitor ou receptor de uma tecnologia. As várias possibilidades de comunicação e produção de conhecimento que as novas tecnologias apresentam solicitam aos utilizadores uma posição ativa nos processos de uso dos quais participa.

Quanto mais uso fazemos desses novos aparatos tecnológicos, mais apropriações efetivamos, que reverberam no desenvolvimento de um novo ethos (BUZATO, 2009b). Isso significa ocorrência ou potencialidade de transformação social, ancorada em participação, distribuição, experimentação, colaboração e hibridismo, que marcam as práticas de letramentos digitais dos sujeitos, sendo estes produtores e resultado das apropriações da cultura digital em que estão inseridos (LANKSHEAR; KNOBEL, 2005).

Sobre a apropriação, Buzato (2009b) nos adverte que esta pode apresentar sentidos distintos quando posta em processo. Um deles diz respeito à apropriação como internalização da tecnologia, que, sendo objeto exterior ao sujeito, possui habilidades próprias que podem ser transmitidas a este. Por outro lado, também como objeto exterior, pode ser vista como um meio que está a serviço do sujeito, o qual a importa e a transforma de acordo com as suas necessidades. Por último, a apropriação da tecnologia é participativa, na ocasião em que "as pessoas adaptam e modificam o seu significado por meio da interação social (negociação de sentidos) em torno dos usos da tecnologia. Apropriação, portanto, passa de uma recondição a um sinônimo de transformação. Apropriar-se é igual a tornar-se (becoming)" (BUZATO, 2009b, p. 4-5) 
Por este prisma, a tecnologia é desenvolvida de maneira mais aberta, e a apropriação é pensada não somente no esquema tradicional, de cima para baixo (desenvolvedor-usúario): o movimento de baixo para cima (usuário-desenvolvedor) também é válido e carrega potencialidades nas relações que os sujeitos estabelecem com os outros e com os meios tecnológicos. Aqui, outros sentidos e possibilidades de usos são construídos nos próprios usos.

Diante desses pressupostos, preconiza-se que as instituições educativas, os professores, os alunos e as formas de ensinar e aprender já não são mais os mesmos. Sendo outros, requerem novas intencionalidades educativas que atendam às necessidades cognitivas estimuladas pelas inovações tecnológicas, como destaca Hargreaves (2004).

A relação com o saber é alterada, os professores e alunos já não são somente receptores de informações, são construtores ativos na busca pelo conhecimento. Por isso, é "fundamental que o professor insira as TDIC na organização do trabalho pedagógico, a fim de motivar o aprender a aprender mediado pela diversidade de recursos tecnológicos" (SILVA, 2011, p. 41).

Para tanto, o uso das TDIC deve superar a perspectiva de domínio puramente técnico. Sobretudo, deve enveredar-se por caminhos que favoreçam a reconstrução de velhas práticas educativas (COUTINHO; LISBOA, 2011; PORTO, 2006; KENSKI, 2007), com um novo professor que esteja alinhado a essas novas demandas processuais da inclusão digital e busque mecanismos de usos e apropriações dos recursos digitais.

A formação desse professor mostra-se como lugar privilegiado para a construção dessas perspectivas. Os cursos de formação devem funcionar então como espaços de efetivação e reverberação de outras práticas de leitura e escrita, visto que formam agentes de letramento que precisam se apropriar das novas formas de ler e escrever (KLEIMAN, 2007) e conhecer as linguagens e os gêneros digitais que norteiam as práticas de seus alunos. As práticas de leitura e escrita na academia, que são marcas identitárias da formação universitária, precisam refletir as mudanças provocadas pelos novos gêneros digitais. Mais ainda, sabendo que se atuará nas escolas com alunos nativos digitais, a formação precisa estar ancorada nesses formatos do letrar-se digitalmente.

\section{Procedimentos da Revisão Sistemática}

Pensando nas escolhas de técnicas e procedimentos, encontramos no mapeamento sistemático de literatura um importante limítrofe para entender como nosso objeto de estudo tem sido tratado em nível nacional. Por revisão sistemática aqui entendemos a pesquisa que utiliza "dados da literatura sobre determinado tema", como colocam Sampaio e Mancini (2007, p. 84), que tem dentre as muitas vantagens o levantamento de espectros de maior relevância para o estudo, de maneira detalhada e confiável, na bibliografia encontrada. As revisões analisam "um conjunto menor de estudos, pois têm objetivos bastante específicos e focam em aprofundar os conhecimentos já existentes em um determinado tema, como a comparação entre a eficácia de diferentes métodos" (KLOCK, 2018, p. 2). 
É válido destacar ainda que sua qualidade dependerá da fonte dos dados e sua consistência, já que demanda, como em qualquer outra técnica de pesquisa, rigor e análise crítica quanto ao que for levantado (CONFORTO; AMARAL; SILVA, 2011). Nesse sentido, é um método que sugere determinados procedimentos e/ou modelos que são adequados a cada área da ciência, ao tema seguido ou aos recursos disponíveis para sua realização. Conforme assegura Klock (2018), esse tipo de pesquisa deve seguir efetivamente passos de um protocolo previamente estabelecido, o que requer a definição de norteadores de busca bem claros, de maneira a torná-la viável e mais facilitada.

Em busca de elementos de aproximação e estreitamento com o nosso tema em pesquisas nacionais, precisávamos definir o banco de dados e especificar algumas questões que esperávamos encontrar. As equações pontuadas foram: quais objetivos de pesquisa essas produções revelam? Que perspectivas de letramento digital e quais procedimentos e instrumentos metodológicos os pesquisadores adotaram? Quais resultados dos processos de letramento digital trabalhados na formação de professores foram revelados?

Visitamos a Biblioteca Digital Brasileira de Teses e Dissertações (BDTD), sob a chave de busca "letramento digital" na "formação de professores", com descritores nas ciências humanas, educação e linguística. Encontramos 307 dissertações e 129 teses publicadas entre os anos de 2010 e 2018. Desse total, fizemos a leitura dos resumos, com um filtro que excluiu pesquisas que: (1) tratavam dos usos de tecnologias na formação de professores de forma mais abrangente, mas sem discutir diretamente 0 letramento digital; (2) abordavam práticas docentes com usos de tecnologias na educação básica, mas sem foco na formação de professores. Nos voltamos então às 37 pesquisas restantes, sendo 24 dissertações e 13 teses.

\section{Achados}

$\mathrm{Na}$ sistemática de leitura e conhecimento das produções nacionais selecionadas, consideramos pertinentes antes destacar os contextos das pesquisas, referindo lócus definido. A formação inicial ou continuada esteve presente nos cenários analisados pelos pesquisadores: 14 trabalhos trouxeram a formação continuada ou em serviço, e 23 discutiram a formação inicial, conforme podemos ver no Quadro 1.

Quadro 1: Lócus dos trabalhos analisados.

\begin{tabular}{|c|c|}
\hline Lócus & AUTORIANO \\
\hline Formação Inicial & $\begin{array}{l}\text { Hinkel (2014); Custódio (2015); Santos (2015); Falcão (2015); Rezende (2015); Silva } \\
\text { (2015); Alexandre (2015); Pinto (2015); Silva (2016); Barreto (2016); Fadini (2016); } \\
\text { Souza (2016); Araujo (2016); Arroyo (2016); Silva (2017); Vidal (2017); Gonçalves } \\
\text { (2017); Saito (2017); Nascimento (2017); Araújo (2017); Assis (2018); Gonçalves (2018); } \\
\text { Batista (2018) }\end{array}$ \\
\hline $\begin{array}{l}\text { Formação } \\
\text { Continuada / Em } \\
\text { Serviço }\end{array}$ & $\begin{array}{l}\text { Miguel (2014); Junior (2014); Pavanelli (2014); Costa (2015); Ferreira (2015); Bezerra } \\
\text { (2015); Montes (2016); Ramos (2016); Ribeiro (2016); Santos (2016); Silveira (2017); } \\
\text { Nogueira (2017); Barbeta (2017); Sousa (2017). }\end{array}$ \\
\hline
\end{tabular}

Fonte: Elaboração própria. 
Esse dado sugere que os estudos se ocuparam de níveis e segmentos que integram a formação de professores, consagrando a compreensão científica de que esse processo formativo não se esgota em uma única etapa, deve dar-se de forma contínua.

No que se refere à formação inicial, verificamos que 16 trabalhos se concentraram nos cursos de Letras, 4 deles em cursos de Pedagogia, 1 em curso de Ciências, 1 em curso de Ciência e Matemática e 1 em Educação Musical. Essa predominância nos estudos dos cursos de Letras, considerando as justificativas apresentadas pelos pesquisadores, aconteceu pelo próprio objetivo da formação na área, que habilita o profissional para a docência das linguagens. Isso torna positivo discutir as novas problematizações em que este profissional está envolto ao exercer sua atividade profissional com a integração das tecnologias digitais.

No entanto, seguindo essa mesma argumentação, consideramos que se revelou um hiato com relação ao profissional de Pedagogia. Habilitado para atuar com crianças em processo de alfabetização e letramento, ele também precisa desenvolver competências para o trabalho com os processos de aquisição da língua e suas nuances contemporâneas, que incluem o trabalho com as TDIC, para favorecer as aquisições e apropriações a serem feitas pelas crianças. Esse profissional, em referência a Kleiman (2007), é um agente de letramento, sendo relevante problematizar sua formação para atuar na educação infantil e séries iniciais do ensino fundamental.

Quanto aos objetivos, os dados apontaram categorias em relação a: (1) percepções, concepções, crenças e sentidos do letramento digital nos processos formativos dos professores; (2) usos e apropriações das tecnologias digitais para o desenvolvimento do letramento no âmbito da formação; (3) contribuições do trabalho com letramento digital na/para a formação/desenvolvimento do professor. Na primeira categoria, foi possível destacar os trabalhos de 11 pesquisadores, que trouxeram expressamente essas palavraschave ou sinônimos na apresentação de seus objetivos (Quadro 2).

Quadro 2: Trabalhos sobre percepções, concepções, crenças e sentidos do letramento digital nos processos formativos dos professores.

\begin{tabular}{|l|l|}
\hline \multicolumn{1}{|c|}{ Trabalho } & \multicolumn{1}{c|}{ Objetivo do trabalho } \\
\hline PAVANELLI, 2014 & $\begin{array}{l}\text { Analisar os sentidos verificados nos enunciados dos professores sobre o uso das } \\
\text { tecnologias, ponderando também seus apontamentos sobre a formação continuada } \\
\text { para essa finalidade. }\end{array}$ \\
\hline HINKEL, 2014 & $\begin{array}{l}\text { Reconhecer nas trajetórias de alunos e egressos do curso de Letras da Universidade } \\
\text { da Região de Joinville - UNIVILLE - como eles percebem as contribuições de sua } \\
\text { formação inicial para a prática pedagógica no que se refere ao envolvimento com } \\
\text { tecnologias digitais. }\end{array}$ \\
\hline DIAS, 2015 & $\begin{array}{l}\text { Compreender o olhar do aluno em relação aos multiletramentos e tecnologias } \\
\text { digitais da Informação e Comunicação. }\end{array}$ \\
\hline FALCÃO, 2015 & $\begin{array}{l}\text { Estudar professores em formação e crianças entre 9 e 11 anos, relacionando seus } \\
\text { conhecimentos e práticas por meio do uso de TDIC, e se há uma lacuna entre } \\
\text { esses sujeitos, considerando tais conhecimentos. }\end{array}$ \\
\hline BEZERRA, 2015 & $\begin{array}{l}\text { Compreender significados atribuídos por professores da educação básica aos } \\
\text { cursos de formação continuada do NTE na escola acerca do uso das TDIC ao } \\
\text { refletirem sobre suas experiências formativas. }\end{array}$ \\
\hline SILVA, 2016 & Analisar a visão de um grupo de professores e pedagogos acerca do letramento digital. \\
\hline
\end{tabular}




\begin{tabular}{|l|l|}
\hline MONTES, 2016 & $\begin{array}{l}\text { Analisar as percepções e crenças dos professores de uma escola estadual do } \\
\text { município de Divino sobre o uso de TDIC e desenvolver ações que minimizassem a } \\
\text { resistência desses profissionais em usá-las em contexto educacional. }\end{array}$ \\
\hline FADINI, 2016 & $\begin{array}{l}\text { Analisar crenças de professores formadores e de professores de inglês em } \\
\text { formação em um curso de licenciatura em Letras-Inglês de uma universidade federal } \\
\text { do sudeste brasileiro. }\end{array}$ \\
\hline ARAÚJO, 2016 & $\begin{array}{l}\text { Investigar a percepção de quatro alunos-professores de inglês sobre a } \\
\text { aprendizagem e a prática pedagógica com o uso das tecnologias, observando-se } \\
\text { suas percepções acerca da inclusão das tecnologias no ensino-aprendizagem de } \\
\text { inglês bem como o fomento do letramento digital desses alunos-professores a partir } \\
\text { de uma disciplina curricular acadêmica do curso de Letras-Inglês. }\end{array}$ \\
\hline GONÇALVES, 2017 & $\begin{array}{l}\text { Compreender os sentidos, na voz dos acadêmicos de pedagogia para as leituras e } \\
\text { produções escritas em práticas de letramento acadêmico. }\end{array}$ \\
\hline ARAÚJO, 2017 & $\begin{array}{l}\text { Investigar a percepção de quatro alunos-professores de inglês sobre a } \\
\text { aprendizagem e a prática pedagógica com o uso das tecnologias, observando-se } \\
\text { suas percepções acerca da inclusão das tecnologias no ensino-aprendizagem de } \\
\text { inglês bem como o fomento do letramento digital desses alunos-professores a partir } \\
\text { de uma disciplina curricular acadêmica do curso de Letras-Inglês. }\end{array}$ \\
\hline
\end{tabular}

Fonte: Elaboração própria sobre os trabalhos analisados (grifos nossos).

Pesquisar o trabalho e a formação do professor significa pormenorizar as nuances do aprender a ensinar, da identidade e da profissionalidade docente, como nos assevera Nóvoa (1997). Para tanto, é preciso tecer olhares sobre as objetividades e subjetividades, pois o trabalho do professor também está envolto em seus pensamentos, emoções, crenças, aprendizagens e ações, e esses aspectos motivaram um movimento para alicerçar a formação de professores como campo de pesquisa.

Zeichner (2005) e Diniz-Pereira (2013) destacam que esse campo é relativamente recente na literatura. Somente entre as décadas de 1970/80 conquistou status e começou a ser problematizado de forma mais ampla, quando o sujeito professor passou a ser considerado nos focos das pesquisas. Isso trouxe a necessidade de análises que ultrapassassem aspectos descritivos, técnicos e operacionais, fazendo aprofundamentos nas subjetividades que o professor constrói ao longo de sua trajetória pessoal e profissional.

Dentre outras agendas nesse contexto complexo e multireferenciado, Zeichner (2005) considera importante buscar formas de avaliar melhor o saber docente, sem dissociá-lo do contexto e das práticas, que são genuinamente os espaços de sua produção. Diríamos que não há como apreender e qualificar as ações dos sujeitos sem verificar a orientação e os fundamentos que eles exprimem em suas concepções e nos significados que atribuem a algo, visto que estes são elementos da identidade e profissionalização dos professores.

A nosso ver, há preocupação nos trabalhos destacados com essa pormenorização, situando uma realidade emergente em contextos educativos com inserção das tecnologias digitais para o letramento. A preocupação em situar os letramentos concebidos pelos sujeitos desvenda as compreensões em que são construídos e os significados atribuídos, ou ainda, segundo Gee (2009), constitui uma posição perante o fenômeno social.

O segundo enquadramento dos objetivos traz uma perspectiva da prática dos sujeitos, que categorizamos como usos e apropriações das tecnologias digitais para o desenvolvimento do letramento no âmbito da formação. Aqui, destacamos 20 trabalhos (Quadro 3). 
Quadro 3: Trabalhos sobre usos e apropriações das tecnologias digitais para o desenvolvimento do letramento no âmbito da formação.

\begin{tabular}{|c|c|}
\hline Trabalho & Objetivo do trabalho \\
\hline MIGUEL, 2014 & $\begin{array}{l}\text { Verificar quais são as práticas, modos de uso, consumo, apropriação e produção } \\
\text { dos recursos digitais pelos docentes e como a formação e o acompanhamento } \\
\text { pedagógico podem influenciar/ampliar a apropriação qualificada das mídias em suas } \\
\text { práticas pedagógicas. }\end{array}$ \\
\hline JUNIOR, 2014 & $\begin{array}{l}\text { Investigar a influência da formação continuada para o letramento digital na prática } \\
\text { pedagógica dos professores dos anos iniciais do ensino fundamental da Rede } \\
\text { Municipal de Educação de Manaus-AM. }\end{array}$ \\
\hline CUSTÓDIO, 2014 & $\begin{array}{l}\text { Analisar o desenvolvimento do letramento informacional digital de professores em } \\
\text { formação inicial do curso de letras de uma instituição de ensino superior, observando o } \\
\text { processo busca por ferramentas online para o planejamento do ensino de línguas. }\end{array}$ \\
\hline FERREIRA, 2015 & $\begin{array}{l}\text { Analisar e caracterizar os fóruns de discussão no ambiente Moodle do } \\
\text { PNAIC/UFSCar no ano de 2014, levando em consideração a forma de interação } \\
\text { propiciada pelo gênero em questão, focando também o letramento digital dos } \\
\text { Orientadores de Estudo. }\end{array}$ \\
\hline REZENDE, 2015 & $\begin{array}{l}\text { Investigar como se dá a formação de professores de língua portuguesa na UEL, } \\
\text { para a implementação das novas práticas letradas com forte apelo tecnológico. }\end{array}$ \\
\hline PINTO, 2015 & $\begin{array}{l}\text { Sistematizar e discutir o estado da arte de pesquisas sobre letramentos digitais no que } \\
\text { se referem as práticas pedagógicas de professores de lingas em formação. }\end{array}$ \\
\hline COSTA, 2015 & $\begin{array}{l}\text { Investigar sobre um curso de formação docente para professores de Ensino } \\
\text { Fundamental da escola pública, levando-se em conta conceitos sobre treinamento e } \\
\text { formação continuada. }\end{array}$ \\
\hline SILVA, 2015 & $\begin{array}{l}\text { Discutir os desafios, as possibilidades e o processo de formação continuada do } \\
\text { professor para promover o ensino de Língua Portuguesa em ambientes digitais e } \\
\text { virtuais na modalidade presencial. }\end{array}$ \\
\hline BARRETO, 2016 & $\begin{array}{l}\text { Analisar a formação do professor de inglês orientado à integração das mídias no } \\
\text { contexto do estágio supervisionado. }\end{array}$ \\
\hline RIBEIRO, 2016 & $\begin{array}{l}\text { Desenvolver um curso de Letramento Informacional e Midiático (LIM) para formação } \\
\text { continuada de professores atuantes na Educação Básica, que foi construído alicerçado } \\
\text { nas abordagens de Design Thinking para Educadores e no Experience Learning. }\end{array}$ \\
\hline ARROYO, 2016 & $\begin{array}{l}\text { Investigar o estatuto do link (popularmente conhecido como "ligação eletrônica" em } \\
\text { hipertextos da internet) como ponto de heterogeneidade de práticas letradas } \\
\text { acadêmicas em contexto digital. }\end{array}$ \\
\hline SILVA, 2017 & $\begin{array}{l}\text { Analisar como o curso de licenciatura em letras incorpora o letramento digital, com } \\
\text { ênfase no estágio supervisionado }\end{array}$ \\
\hline SILVEIRA, 2017 & $\begin{array}{l}\text { Elaborar um tutorial para o letramento midiático e digital do professor no } \\
\text { desenvolvimento do projeto rádio escolar. }\end{array}$ \\
\hline VIDAL, 2017 & Investigar o uso das simulações virtuais como alternativa metodológica ao ensino de Ciências. \\
\hline SAITO, 2017 & $\begin{array}{l}\text { Investigar os processos de co-construções webcurriculares em um curso de língua } \\
\text { inglesa, e cujas construções das aulas são mediatizadas pelas tecnologias da } \\
\text { informação e comunicação, suas ferramentas e seus recursos. }\end{array}$ \\
\hline $\begin{array}{l}\text { NOGUEIRA, } \\
2017\end{array}$ & $\begin{array}{l}\text { Analisar de que maneira os professores de língua inglesa do ensino médio da rede } \\
\text { pública estadual de São Paulo estão conseguindo utilizar nas aulas os } \\
\text { conhecimentos construídos nos cursos oferecidos pela Secretaria Estadual de } \\
\text { Educação e pelos Núcleos Pedagógicos, que envolvem tecnologia educacional e a } \\
\text { "Plataforma Currículo+". }\end{array}$ \\
\hline
\end{tabular}




\begin{tabular}{|l|l|}
\hline BARBETA, 2017 & $\begin{array}{l}\text { Intervir junto a dois professores do ensino médio de uma escola pública estadual da } \\
\text { cidade Londrina-PR. }\end{array}$ \\
\hline $\begin{array}{l}\text { NASCIMENTO, } \\
2017\end{array}$ & $\begin{array}{l}\text { Investigar o quanto e de que forma o Pibid de uma Universidade do Nordeste } \\
\text { brasileiro permite o trabalho com o letramento digital na formação inicial do } \\
\text { professor de inglês. }\end{array}$ \\
\hline $\begin{array}{l}\text { GONÇALVES, } \\
2018\end{array}$ & $\begin{array}{l}\text { Compreender práticas de letramentos acadêmicos com TD desenvolvidas no LIFE } \\
\text { por docentes universitários com professores em formação inicial e continuada. }\end{array}$ \\
\hline ASSIS, 2018 & $\begin{array}{l}\text { Analisar o processo de implementação do projeto Early Bird como flagrante das } \\
\text { disputas e polêmicas que envolvem o campo da formação de professores no Brasil, } \\
\text { mais especificamente a formação de professores de LIC. }\end{array}$ \\
\hline
\end{tabular}

Fonte: Elaboração própria sobre os trabalhos analisados (grifos nossos).

A tecnologia digital em contexto educacional solicita aos professores usos eficientes, o que requer apropriações para o desenvolvimento das práticas docentes (KLEIMAN, 2007). Investigando as práticas ou eventos de letramento digital na formação dos professores, esses pesquisadores destacaram a construção de competências digitais que podem ser suscitadas, considerando os contextos institucionais, as possibilidades e especificidades na utilização das tecnologias.

Nesse viés, pressupomos que esses pesquisadores partem do entendimento de que o fazer docente não é meramente uma dimensão técnica, e sim articula diversas dimensões, e que todo processo de ensino-aprendizagem passa por definições curriculares, por organização institucional e pelas experiências de cunho pessoal e profissional dos docentes e discentes, que emergem na dinâmica do fazer pedagógico com o auxílio dos recursos tecnológicos. Ou seja, essas ações expressam os direcionamentos e criações curriculares fundamentadas na cibercultura, que carregam em si condicionamentos oriundos de seus usos.

Pensamos que os usos, para além das crenças e concepções da primeira categoria descrita, apresentam um campo ainda mais fértil, que se correlaciona com as possibilidades que as tecnologias e o campo pedagógico carregam. É por meio dos usos que as apropriações podem ser sentidas, significadas e ressignificadas. É por meio dos usos que poderemos interrogar suas contribuições e apropriações para este ou aquele objetivo educativo, para este ou aquele processo formativo.

No entanto, não qualquer uso. Quando falamos de letramento digital, não nos referimos a um simples domínio técnico ou a uma habilidade ligada à tecnologia, estamos tratando de práticas sociais específicas construídas em atividades que envolvem a relação e a comunicação entre sujeitos, ou, como coloca Buzato (2006), práticas sociais que conectam e apropriam por meio dos recursos digitais.

Estudar os usos das TDIC no âmbito da formação de professores é uma justificação do crescente consenso entre os pesquisadores quanto à importância de conhecer os percursos possíveis, que modificam o que sabíamos e o que precisamos saber a respeito desse assunto, e de suas implicações quanto aos usos e apropriações que fazemos. Integrar as novas tecnologias ao conjunto de práticas formativas habilita o professor em formação para novos conhecimentos e conversões necessárias.

Investigando esses aspectos, os trabalhos trazem indícios sobre os caminhos tomados pelos sujeitos da pesquisa na construção de sua identidade letrada, aclarando trajetórias de aprendizagem, usos e apropriações das tecnologias nos processos 
realizados nessa construção. É uma tendência investigativa sobre letramento digital, que segundo Buzato (2009b, p. 11), pretende "legitimar as maneiras locais pelas quais cada professor, com seus alunos, possa se apropriar das novas tecnologias de modo a negociar criativamente os designs e configurações curriculares, didáticos e espaciotemporais".

A ciência não pode prescindir dessas investigações. E pensamos que foi esse o intuito desses trabalhos que buscaram verificar para além do acesso às tecnologias digitais na formação de professores, no descortinar das práticas docentes e seus diferentes letramentos.

Nesse movimento, é preciso assinalar os diferentes efeitos produzidos cognitiva e socialmente. Pensando nesses efeitos, trazemos a terceira categoria, de contribuições do trabalho com letramento digital na/para a formação/desenvolvimento do professor", apresentada nos objetivos de sete trabalhos (Quadro 4).

Quadro 4: Trabalhos sobre contribuições do trabalho com letramento digital na/para a formação/desenvolvimento do professor.

\begin{tabular}{|c|c|}
\hline Trabalho & Objetivo do trabalho \\
\hline SANTOS, 2015 & $\begin{array}{l}\text { Refletir sobre o conhecimento construído a respeito da formação inicial em letras } \\
\text { em relação ao letramento digital pelos professores na UEL. }\end{array}$ \\
\hline ALEXANDRE, 2015 & $\begin{array}{l}\text { Analisar a contribuição da integralização curricular do Curso de Pedagogia da } \\
\text { UFC na formação dos saberes tecnológicos de seus professores. }\end{array}$ \\
\hline RAMOS, 2016 & $\begin{array}{l}\text { Investigar as contribuições de um curso de formação contínua para elaboração } \\
\text { de material educacional digital (MED), intitulado Elaboração de Material Educacional } \\
\text { Digital - Nível Básico, para o letramento digital de professores de inglês. }\end{array}$ \\
\hline SANTOS, 2016 & $\begin{array}{l}\text { Analisar o processo de desenvolvimento profissional dos docentes para a } \\
\text { utilização das tecnologias de informação e comunicação (TIC) através da análise e } \\
\text { descrição da proposta do curso, das dimensões de desenvolvimento profissional e da } \\
\text { verificação das contribuições concretas do curso para os docentes. }\end{array}$ \\
\hline SOUZA, 2016 & $\begin{array}{l}\text { Analisar o processo de formação de estudantes online (idealização, práticas e } \\
\text { discursos) ao uso das mídias digitais (MD), identificando a relação entre as competências } \\
\text { a desenvolver nos estudantes e as dimensões, conhecimentos e habilidades mobilizadas } \\
\text { durante a formação que se configuram em Letramentos Digitais (LD), destacando as } \\
\text { contribuições para propostas de formação ao contexto brasileiro. }\end{array}$ \\
\hline SOUSA, 2017 & $\begin{array}{l}\text { Analisar indícios de conhecimentos para a prática pedagógica docente } \\
\text { interdisciplinar, emergentes em um contexto colaborativo de formação continuada na } \\
\text { perspectiva do letramento. }\end{array}$ \\
\hline BATISTA, 2018 & $\begin{array}{l}\text { Compreender como a memória digital se apresenta na modalidade de educação a } \\
\text { que se denomina educação a distância (EaD) foi o objetivo da tese, de modo que se } \\
\text { pôde analisar como ela interfere neste contexto, e a partir de então, refletir a } \\
\text { respeito da formação em uma sociedade marcada pelas tecnologias do digital. }\end{array}$ \\
\hline
\end{tabular}

Fonte: Elaboração própria sobre os trabalhos analisados (grifos nossos).

Construção de conhecimentos, habilidades e desenvolvimento profissional denotam as contribuições dos percursos formativos com uso de tecnologias digitais para o letramento, sendo frutos das reflexões sobre a prática docente que podem, por assim dizer, potencializar outras alternativas de ação. 
Ao buscarem as contribuições do letramento digital na formação, esses pesquisadores pareceram estar preocupados em desvelar, e não em reforçar ou prescrever, a forte demanda de inserção das tecnologias no processo educativo e em apresentar as mudanças qualitativas que os usos das tecnologias para o letramento digital fornecem ao processo pedagógico, modificando e alargando as possibilidades de usos em cada contexto social.

Segundo Kenski (2007), esses usos podem ser vistos como elemento estruturante de um novo fazer pedagógico que, nesse sentido, somente pode ser construído nas apropriações que se formam no próprio processo. A construção de conhecimentos e habilidades se dá na prática social, na participação em um processo, com vistas ao desenvolvimento profissional.

É preciso projetar uma formação que atenda a esses novos contextos, e os apontamentos dessas pesquisas abrem caminhos para fortalecer as dinâmicas formativas e trazer perspectivas diferentes à prática docente. Para que a prática docente não seja uma mera reprodução, é preciso aprofundar estudos como esses, que destaquem as contribuições que os recursos ou interfaces pedagógicas desencadeiam.

Diante das diferentes categorizações dos objetivos das pesquisas, verificamos a adoção de alguns termos associados ao letramento digital (Figura 1).

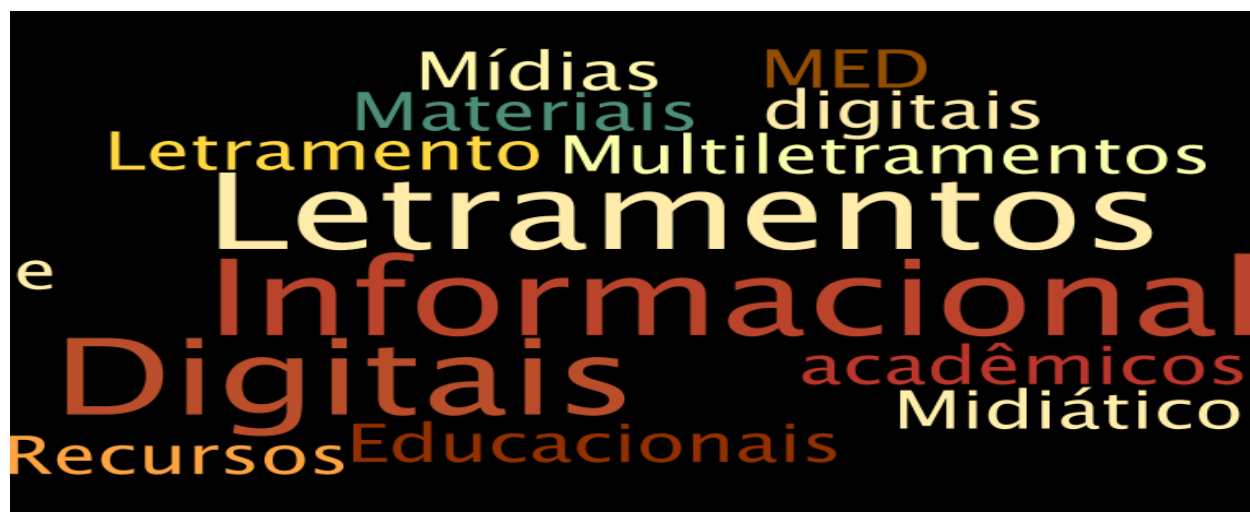

Figura 1: Palavras associativas.

Fonte: Nuvem de palavras elaborada pela autora.

Os termos associados à discussão sobre o letramento revelam as perspectivas teóricas adotadas. A maioria dos trabalhos ancora suas concepções e fundamentação teórica na perspectiva dos novos letramentos, tendo como referenciais mais recorrentes autores que discutem essa questão, a exemplo de Lankshear; Knobel (2005), Gee (2009), Street (2014), Buzato (2006, 2009a; 2009b), Coscarelli; Ribeiro (2011), Soares (2002), entre outros que entendem o letramento como prática social.

Vale destacar ainda a variação dos aportes metodológicos adotados. Entre 33 pesquisas qualitativas e 4 qualiquantitativas, encontramos 13 pesquisas-ação, 2 etnográficas, 4 estudos de caso, 1 bibliográfica e as demais 17 se definiram apenas como qualitativas. Os instrumentos de coleta de dados mais utilizados foram as entrevistas semiestruturadas, o questionário e a observação participante.

Os contextos e sujeitos informantes desses trabalhos também foram variados: professores-formadores, coordenadores de cursos, gestores, alunos-formandos ou 
professores. Isso nos dá um panorama abrangente sobre as ocorrências e as singularidades do fenômeno do letramento digital na formação de professores.

Nos percursos metodológicos, a formação foi pesquisada por meio dos ou com os usos de tecnologias para o letramento digital, fomentando resultados e agendas de pesquisa que se voltam à autenticação da relevância das tecnologias digitais no trabalho com o letramento em contextos educacionais; ao fomento das potencialidades que os usos trouxeram e poderão trazer à prática e ao desenvolvimento profissional; e à indicação da necessidade de que as propostas formativas trabalhem outros aspectos, desenvolvam outras dimensões e habilidades nos formadores e formandos para além da operacional, de forma que viabilizem maiores apreensões e transposições à prática dos professores.

Para ilustrarmos os pontos que acabamos de destacar, trazemos enxertos com as potencialidades ou lacunas constatadas pelas pesquisas em relação ao fenômeno (Quadro 5).

Quadro 5: Potencialidades e lacunas identificadas pelos trabalhos analisados.

\begin{tabular}{|c|c|}
\hline Trabalho & Potencialidades/lacunas \\
\hline HINKEL, 2014 & $\begin{array}{l}\text { Contudo, recebeu destaque pelos participantes o aprendizado que ocorreu em } \\
\text { casa e por meio do autoestudo e da prática. Além disso, foi possível perceber que } \\
\text { as práticas digitais estão presentes no dia a dia dos estudantes, com destaque à } \\
\text { leitura e escrita em tela, e também na sua vida acadêmica. Essa fornece situações } \\
\text { que possibilitam uma ampliação de sua gama de práticas digitais, inclusive a noção } \\
\text { dos seus usos como ferramenta pedagógica, mesmo o curso não oferecendo uma } \\
\text { disciplina específica. }\end{array}$ \\
\hline MENDES, 2017 & $\begin{array}{l}\text { Por fim, conclui-se que o modelo dos Letramentos Acadêmicos articula-se com as } \\
\text { TD no que diz respeito à ressignificação das práticas de letramentos e das } \\
\text { práticas pedagógicas, no contexto investigado, uma vez que ambos possibilitam } \\
\text { novas relações de poder entre os sujeitos e com o conhecimento. }\end{array}$ \\
\hline SILVA, 2015 & $\begin{array}{l}\text { Uma vez que as possibilidades de trabalho com as TIC são inúmeras, o } \\
\text { professor, por meio de um processo de formação continuada reflexivo, pode } \\
\text { alcançar o letramento digital necessário para a elaboração de atividades de } \\
\text { língua portuguesa em contextos digitais presenciais, de forma a propiciar aos alunos } \\
\text { o conhecimento não só dos recursos linguísticos, mas também dos recursos } \\
\text { tecnológicos necessários para que eles sejam bem-sucedidos nas diversas esferas } \\
\text { comunicativas ao longo de suas vidas. }\end{array}$ \\
\hline SILVA, 2016 & $\begin{array}{l}\text { A partir de tais limitações, ressalta-se a necessidade de uma proposta de } \\
\text { formação docente (inicial, continuada e em serviço) que contemple aspectos } \\
\text { técnicos e pedagógicos das tecnologias, bem como que contribua para uma } \\
\text { reflexão em torno dos modos como tais tecnologias são concebidas, utilizadas e } \\
\text { mediadas nas práticas sociais. Isto é, uma formação docente que busque } \\
\text { desenvolver o letramento digital. }\end{array}$ \\
\hline REZENDE, 2015 & $\begin{array}{l}\text { O trabalho de intervenção revelou que houve mudanças nas perspectivas dos } \\
\text { professores em formação inicial e também do professor-pesquisador, mas que é } \\
\text { preciso que todo o processo de formação de professores se mobilize nessa } \\
\text { direção para que a realidade do ensino seja modificada satisfatoriamente. }\end{array}$ \\
\hline ARAÚJO, 2017 & $\begin{array}{l}\text { Nessa vertente, os dados mostram que a disciplina sobre tecnologias cumpriu } \\
\text { uma de suas funções no currículo do curso de licenciatura Letras-Inglês ao } \\
\text { promover, a partir de práticas reflexivas, o letramento digital dos participantes }\end{array}$ \\
\hline
\end{tabular}




\begin{tabular}{|l|l|}
\hline & $\begin{array}{l}\text { por meio da familiarização de diversas interfaces tecnológicas digitais para } \\
\text { propósitos educacionais que eram desconhecidas por eles no início da } \\
\text { disciplina. Defende-se, assim, que as TDIC trazem múltiplas vantagens ao serem } \\
\text { incorporadas à pedagogia da sala de aula de maneira reflexiva, funcional e crítica no } \\
\text { curso de Letras, trazendo contribuições importantes para a formação inicial de } \\
\text { professores de inglês. }\end{array}$ \\
\hline SOUZA, 2016 & $\begin{array}{l}\text { Por fim, a questão de pesquisa se confirmou ao apontar que os LD na cibercultura } \\
\text { implicam tanto a apropriação das novas linguagens do meio digital, quanto à } \\
\text { prática efetiva de seu uso social destas em que eventos que convergem diversos } \\
\text { meios, recursos, interfaces, gêneros e linguagens digitais, e podem ser } \\
\text { potencializadas na formação de estudantes online na universidade. }\end{array}$ \\
\hline
\end{tabular}

Fonte: Elaboração própria sobre os trabalhos analisados (grifos nossos).

Esses resultados contemplam os dilemas e desafios com que a formação de professores se depara, como também os caminhos traçados para atender minimamente aos saberes que os alunos-professores precisam desenvolver, diante das dinâmicas que o letramento digital no contexto educativo pressupõe. Há um reconhecimento de que as formações precisam dar conta dessa demanda de inclusão digital, mas também há reconhecimento que estas estão efetivando alguns processos de usos das TDIC.

Para os pesquisadores, os cursos precisam rever diretrizes, os currículos precisam prever essa perspectiva, as disciplinas precisam dialogar sobre essa questão e os professores precisam ser capacitados para apropriações e adoções de tecnologias em suas práticas. Nesse prisma, as competências digitais reduzidas do professor podem ser ampliadas e o conhecimento construído de maneira individualizada podem ser superados.

\section{Considerações finais}

Este texto apresentou o resultado de uma revisão sistemática que identificou as teses e dissertações publicadas entre 2010 e 2018 sobre o letramento digital na formação de professores, com o auxílio do software Parsifal.

Sobre o letramento digital, vimos que as novas tecnologias trouxeram alterações aos processos de apropriação da leitura e escrita, requerendo outras práticas nos contextos formativos, de forma que sejam desenvolvidas competências para os usos e as apropriações do novo trazido pelas TDIC.

Os cursos de formação inicial ou continuada têm inserido as tecnologias digitais, mas são muitas as possibilidades de usos ainda não exploradas. Essa questão foi pontuada nas pesquisas, ao mesmo tempo em que levantava elementos da realidade pesquisada, com seus avanços ou lacunas no trabalho com o letramento. Isso também sugere outros olhares e caminhos para as investigações sobre a temática, caminhos que invistam tanto na visão de professores e alunos sobre as tecnologias quanto nas apropriações que se promovem.

A revisão sistemática favoreceu um panorama pertinente sobre o que se tem pesquisado nessa questão, permitindo dizer que ainda temos um número reduzido de trabalhos sobre o tema e que esse campo revela-se bem fértil, visto que, quanto mais se utiliza as TDIC nos processos educativos, mais podemos problematizar e empreender 
estudos científicos. Como trabalhos futuros, sugerimos a ampliação dos bancos de dados e tipos de trabalhos no planejamento da pesquisa.

\section{Referências}

BUZATO, M. E. K. Letramentos Digitais e Formação de Professores. In: III Congresso Ibero-Americano EducaRede, 2006, São Paulo. Anais do III Congresso Ibero-Americano EducaRede. São Paulo: CENPEC, 2006, p. 81-86. Disponível em: https://www.academia.edu/RegisterToDownload\#Download. Acesso em 10 abr. 2019.

BUZATO, M. E. K.. Letramento e inclusão: do estado-nação à era das TIC. D.E.L.T.A., São Paulo, vol. 25, n. 1, 2009a, p. 1-38. Disponível em: https://bit.ly/2Yj6tsf. Acesso em: 20 set. 2018.

BUZATO, M. E. K. Letramentos digitais, apropriação tecnológica e inovação. In: III Encontro Nacional sobre Hipertexto, 2009b, Belo Horizonte. Anais... Belo Horizonte: CEFET-MG, 2009b, 12p. Disponível em: https://bit.ly/2vOnMFu. Acesso em 27 nov. 2018.

CARDON, D. A inovação pelo uso. In: AMBROSI, A.; PEUGEOT, V.; PIMIENTA, D. (coord.). Desafios de Palavras: Enfoques Multiculturais sobre as Sociedades da Informação. Caen-France: C \& F Éditions, 2005, s/p. Disponível em: https://vecam.org/archives/article591.html. Acesso em 23 abr. 2019.

CONFORTO, E. C.; AMARAL, D. C.; SILVA, S. L. Roteiro para Revisão Bibliográfica Sistemática: Aplicação no Desenvolvimento de Produtos e Gerenciamento de Projetos. In: Anais do $8^{\circ}$ Congresso de Brasileiro de Gestão de Desenvolvimento de Produto (CBGDP), Porto Alegre, 2011. p. 01-12, 2011.

COSCARELLI, C.; RIBEIRO, A. E. Letramento digital: aspectos sociais e possibilidades pedagógicas. 3. ed. Belo Horizonte: Ceale: Autêntica, 2011.

COUTINHO, C.; LISBOA, E. Sociedade da informação, do conhecimento e da aprendizagem: desafios para educação no século XXI. Revista de Educação, v. XVIII, n. 1, p. 5-22, 2011. Disponível em: https://bit.ly/2hzjScw. Acesso em: 10 nov. 2016.

DINIZ-PEREIRA, J. E. A construção do campo da pesquisa sobre formação de professores. Revista da FAEEBA - Educação e Contemporaneidade, Salvador, v. 22, n. 40, p. 145-154, jul./dez. 2013. Disponível em: https://www.revistas.uneb.br/index.php/faeeba/article/view/758/531. Acesso em: 21 dez. 2018.

FREITAS, M. T. Letramento digital e formação de professores. Educação em Revista, Belo Horizonte, v. 26, n. 3, p. 335-352, dez. 2010. Disponível em: http://www.scielo.br/pdf/edur/v26n3/v26n3a17 . Acesso em: 13 fev. 2017. 
GEE, J. P. A situated sociocultural approach to literacy and technology. 2009. Disponível em: https://bit.ly/2H9H7Yc. Acesso em: 2 set. 2014.

HARGREAVES, A. O Ensino na sociedade do conhecimento: a educação na era da insegurança. Porto Alegre: Artmed, 2004.

INSTITUTO BRASILEIRO DE INFORMAÇÃO EM CIÊNCIA E TECNOLOGIA (IBICT). Biblioteca Digital Brasileira de Teses e Dissertações. Disponível em: http://bdtd.ibict.br/vufind/. Acesso em: 10 jan. 2017.

KENSKI, V. M. Educação e tecnologias: o novo ritmo da informação. Campinas; São Paulo: Papirus, 2007.

KLEIMAN, A. B. Letramento e suas implicações para o ensino de língua materna. Signo. Santa Cruz do Sul, v. 32 n 53, p. 1-25, dez. 2007. Disponível em: https://online.unisc.br/seer/index.php/signo/article/viewFile/242/196. Acesso em 13 set. 2018.

KLOCK, A. C. T. Mapeamentos e Revisões Sistemáticos da Literatura: um Guia Teórico e Prático. Revista Cadernos de Informática, v. 10, n. 1, p. 1-9, 2018. Disponível em: https://bit.ly/2vL2ubJ. Acesso em 10 fev.. 2018.

LANKSHEAR, C; KNOBEL, M. Digital Literacies: policy, pedagogy and research considerations for education. 2005. Disponível em: https://bit.ly/2VqbBht. Acesso em 10 dez. 2018.

MOITA-LOPES, L. P. O novo ethos dos letramentos digitais: modos de construir sentido, revolução das relações e performances identitárias fluidas. In: SIGNORINI, I., FIAD, R. S. (org.). Ensino de língua: das reformas, das inquietações e dos desafios. Belo Horizonte: Editora UFMG, 2012. p. 204-229.

NóvOA, A. (org.). Os professores e a sua formação. 3. ed. Lisboa, PT: Dom Quixote, 1997.

PORTO, T. M. E. As tecnologias de comunicação e informação na escola, relações possíveis, relações construídas. Revista Brasileira de Educação, v. 11, n. 31, p. 43-57, jan./abr. 2006. Disponível em: http://www.scielo.br/pdf/rbedu/v11n31/a05v11n31.pdf. Acesso em: 15 nov. 2016.

SAMPAIO, R. F.; MANCINI, M. C. Estudos de Revisão Sistemática: Um Guia para Síntese Criteriosa da Evidência Científica. Rev. Bras. Fisioter. São Carlos, v. 11, n. 1, p. 83-89, 2007. Disponível em: https://bit.ly/2rsTbJa. Acesso em: 25 set. 2018.

SILVA, I. M. M. Tecnologias e letramento digital: navegando rumo aos desafios. ETD Educ. Tem. Dig., Campinas, v. 13, n. 1, p. 27-43, jul./dez. 2011. Disponível em: https://periodicos.sbu.unicamp.br/ojs/index.php/etd/article/view/1164/1179. Acesso em: 15 nov. 2016. 
SOARES, M. Novas práticas de leitura e escrita: letramento na cibercultura. Educação e Sociedade, Campinas, v. 23, n. 81 p. 143-160, dez. 2002. Disponível em: http://www.scielo.br/pdf/es/v23n81/13935.pdf. Acesso em 10 nov. 2018.

STREET, B. Letramentos sociais: abordagens críticas do letramento no desenvolvimento, na etnografia e na educação. Tradução: Marcos Bagno. São Paulo: Parábola Editorial, 2014.

XAVIER, A. C. S. Letramento digital e ensino. 2005. In: SANTOS, C. F.; MENDONÇA, M. (org.). Alfabetização e Letramento: conceitos e relações. Belo Horizonte: Autêntica, 2005, v. 1. p. 133-148.

ZEICHNER, K. A research agenda for teacher education. In: COCHRAN-SMITH, M.; ZEICHNER, K. (ed.). Studying teacher education: the report of the AERA panel on research and teacher education. London: Lawrence Erlbaum, 2005. p. 737-759. Disponível em: https://bit.ly/2H8AkOy. Acesso em: 10 nov. 2018.

Recebido em dia 06 de abril de 2019. Aprovado em dia 29 de abril de 2019. 